\title{
Illness Behavior: Prediction by Symptoms, the Grossarth-Maticek and Eysenck Personality Types, Neuroticism, Life Events, Coping, Health Locus of Control, Social Support, and Attribution Style
}

\author{
Santos Orejudo Hernández ${ }^{1}$, María Xesús Froján Parga², and Carmen Malo Aznar ${ }^{3}$ \\ ${ }^{1}$ Universidad de Zaragoza \\ ${ }^{2}$ Universidad Autónoma de Madrid \\ ${ }^{3}$ Servicio de Salud Pública. Gobierno de Aragón
}

\begin{abstract}
A study was carried out with 501 persons to analyze the predictive capacity of various psychosocial variables-symptom perception, neuroticism, Personality Types 2 and 4 of Grossarth-Maticek and Eysenck, beliefs about health, social support, or certain coping styles-on two health-related behaviors: the frequency of visits to the doctor and self-medication. The results were analyzed by two structural equation models that revealed that some of the variables have direct effects on the behaviors, whereas other variables, such as attribution style, coping styles, or the impact of the stressors, have indirect effects via the reported symptoms or neuroticism. In addition, selfmedication and the frequency of health service visits are independent of each other, which shows that their determinants are different. It is concluded that to address these factors in the two health indicators, it is also necessary to take in account the psychosocial variables considered herein. Keywords: personality types, illness behavior, coping styles, self-medication, symptom complaints
\end{abstract}

Se ha llevado a cabo un estudio con 501 personas en el que se intenta analizar la capacidad predictiva de algunas variables psicosociales-la percepción de síntomas, el neuroticismo, los tipos de personalidad 2 y 4 de Grossarth-Maticek y Eysenck, las creencias sobre la salud, el apoyo social y algunos estilos de afrontamiento - sobre dos conductas relacionadas con la salud, la frecuencia de visitas al médico y la automedicación. Los resultados han sido analizados a través de dos modelos de ecuaciones estructurales que ponen de manifiesto que algunas de las variables predictoras tienen efectos directos sobre las conductas consideradas, mientras que otras lo hacen de manera indirecta a través de los síntomas informados o del neuroticismo. Además, la automedicación y la frecuencia de asistencia a los servicios de salud son independientes entre sí, lo que vendría a poner de manifiesto que los determinantes de ambas son distintas, como se comprueba en este trabajo. Se concluye que al abordar los factores implicados en estos dos indicadores de salud, es preciso también tener en cuenta las variables psicosociales aquí consideradas.

Palabras clave: Tipos de personalidad, conducta de enfermedad, estilos de afrontamiento, automedicación, quejas de síntomas

Correspondence concerning this article should be addressed to Santos Orejudo Hernández, Pedro Cerbuna 12, 50009 Zaragoza (Spain). E-mail: sorejudo@unizar.es 
The search for individual psychological differences to explain illnesses has generated a vast field of research. Studies proliferate that support opposing hypotheses: Some suggest the relevance of psychosocial variables in the genesis and evolution of a large number of illnesses and others question and minimize their relevance (Bermúdez, 1999; Friedman, 1990). The concept of health as more than the mere absence of disease has facilitated the use of psychological theories about health to predict various health-related aspects.

Amongst the earliest ones, the theoretical positions are very diverse, especially those referring to the field of personality. Some theories defend the existence of personality types that are prone to illnesses (Friedman \& Roseman, 1959; Grossarth-Maticek, Eysenck, \& Vetter, 1988) or illness processes linked to general traits (Eysenck, 1985). From the cognitive social perspective, there are general health-related personality constructs (Peterson \& Seligman, 1987) and more specific constructs that emerge in this field (Scheier \& Carver, 1992; Wallston, Wallston, Kaplan, \& Maides, 1976). From this perspective, emotional processes are considered to be responsible for the onset of health problems in the population (Kubzansky \& Kawachi, 2000; Smith \& Ruiz, 2002), whereas other perspectives consider stress and the way people cope with it to be the cause of these difficulties, and thus, a predictor of the onset of illness (Petticrew, Fraser, \& Regan, 1999) or of its evolution once it has appeared (RodríguezMarín, Pastor, \& López-Reig, 1993).

Although these perspectives have empirical support, other authors suggest that an approach based solely on one model is insufficient and propose multilevel analysis alternatives in which the prediction of illness or health processes can be performed at several levels of analysis (Pelechano, 2006). In contrast, in other cases, the proliferation of new specific constructs in this field is considered redundant as there are already other constructs and the new ones can hardly improve those that already exist (Kiecolt- Glasser \& Chee, 1991). Within this context, we propose this study. Starting with the hypothesis that psychological variables influence health, we intend to analyze the predictive power of such variables on health-related behaviors - seeking medical care, and self-medication-in order to reveal the independent power of each one of them from a multilevel focus such as the one mentioned above.

The criterion variables selected could be included within the dimension of the concept of illness behavior (Galán, Blanco, \& Pérez, 2000). The most prototypical variable of this concept is seeking medical care, which has traditionally been related to the perception of symptoms. The other dependent variable is self-medication, the personal decision to cope with a symptom without consulting with a professional (Caamaño, Figueiras, Lado, \& Gestal-Otero, 2000). Although these variables do not necessarily correlate with the presence of illness, they are relevant behaviors in the health field, and deserve to be studied from this perspective, which has not received much attention to date.
In the last few decades, one of the most notable controversies has arisen from the publications of Eysenck and Grossarth-Maticek (Eysenck, 1991; Eysenck, GrossarthMaticek, \& Everit, 1991; Grossarth-Maticek et al., 1988), who have reported the surprising results of various studies that show a close relationship between a stress-reaction personality type and certain diseases. They specify four personality types, two of which are related to diseases (Type 1 , related to cancer, and Type 2, related to coronary disease), whereas Types 3, 4, and $4 \mathrm{~b}$ are healthy types. The latest versions of their typology include two new categories, Type 5 , with a predisposition to depression and to cancer, and Type 6 , a protection factor against cancer but with a predisposition to drug use and antisocial behaviors (Grossarth-Maticek \& Eysenck, 1990).

Along with the various publications from the GrossarthMaticek group, other studies have been carried out by independent investigators who have tried to replicate or clarify aspects related to a typology, some of which support their use whereas others cast doubts on some of their hypotheses. Therefore, through comparisons of cases and controls, respective studies and different health indicators, Quander-Blaznik (1991), Schmitz (1992), Sandín, Chorot, Jiménez, and Santed (1994), Smedslung (1995), and Larsson, Nordström, Ljunggren, and Nyberg (1995) support the hypotheses derived from the typology. The Amelang group found favorable results for the healthy typologies but failed to confirm the differential prediction of Types 1 and 2 (Amelang \& Schmitdt-Rathjens, 1996).

Among the multiple issues posed by these papers, one of the most significant, highlighted by Kielcolt-Glaser and Chee (1991), attempts to clarify the extent to which these personality types are different from other constructs coming from the field of stress (such as coping styles, or the performance of risky behaviors) in the prediction of illness. Although the Grossarth-Maticek and Eysenck group has not paid special attention to this topic, other authors have done so, proposing that other variables may prove to be better predictors of the health indicators considered (Amelang, 1997; Rodríguez, Lemos, \& Canga, 2002).

Our work aims to test whether Grossarth-Maticek and Eysenck's typology are better predictors than other psychological variables in the field of health. Until now, the predictive power of other illness-related variables (Amelang, 1997) or attitudes towards health, and life styles (Rodríguez et al., 2002) has been verified, but not that of these behaviors.

According to Eysenck (1985) and in light of their biological roots, his personality dimensions-neuroticism, extroversion, and psychoticism-are related to suffering from certain diseases and reducing the risk factor of other diseases. He specifically related high scores in neuroticism and psychoticism to the risk of cardiovascular diseases and protection against cancer, whereas extraversion is associated with cancer and reduced cardiovascular risk. 
Although from this perspective, neuroticism is considered a stable personality trait. In other cases, it has been considered an indicator of an individual's stable disposition to express negative emotions and it is associated above all with the presence of somatic symptoms and cardiovascular problems (Smith \& Ruiz, 2002; Watson \& Clark, 1984; Watson \& Pennebaker, 1989). In this work, we take on the second position, under the additional hypothesis that other personal variables can explain such emotional arousal.

The health locus of control theory (Wallston et al., 1976) considers that an individual's expectations of control over health-related events act as protectors against diseases (Wallston, Stein, \& Smith, 1994). There are works in which locus of control of illness, together with other variables, allows the discrimination of various degrees of illness (Matthews, Yousfi, Schmidt-Rathjens, \& Amelang, 2003). Health locus of control has also been proposed as one of the possible mediators in the stress process (Barrón \& Chacón, 1990) and in the process of coping with illness as a life event (Andrikowski \& Brady, 1994), as well as another direct predictor of the behavior of seeking medical care upon perceiving symptoms of illness (O'Carrol, Smith, Grubb, Fox, \& Masterton, 2001).

Another psychological construct that has been related to disease is the attribution style (Peterson \& Seligman, 1987). The global-stable dimensions have been related to poorer general health. These results have not always been validated in subsequent studies, which indicates the scanty relevance of these variables in the prediction of levels of health. In contrast, the global and internal attributes are more significant (Dua, 1994).

The construct of stress is of major importance in the attempts to establish a nexus between psychological variables and health. Current models allow for internal cognitive and behavioral processes, such as the cognitive assessment of the stressing agent (demands of the medium) or adaptive strategies used by the individual to cope with such agents or demands (Lazarus \& Folkman, 1984). Yet, another set of variables has been considered, such as genetic differences, personality traits, and social support, which act as modulators of the cognitive assessment of the stimulus, of the coping strategies, and even of the stress response. Of all of these variables, social support seems to play a central role in health processes, either independently or along with other vital events and age, and it is of key importance in the appearance of problems such as cancer (Price et al., 2001) or in the recovery from illness processes (Rodríguez-Marín et al., 1993).

This area has also produced models mediating between stress and some health-related behaviors. Specifically, Cohen and Williamson (1991) proposed a model integrating the perception of symptoms and medical care-seeking behaviors. These authors state that people's higher physiological arousal when stressed facilitates greater attention to internal states and increases the probability of labeling symptoms as signs of disease.
The last variable selected, symptom perception, can be considered a health variable but, at the same time, it is determined by psychological processes, such as those mentioned in the previous model. In this study, rather than focusing on the specific analysis of the psychological determinants of the perception of symptoms, we are interested in the role of this variable as a mediator between psychological factors and the above-mentioned health-related behaviors (Rodríguez-Marín, 1995).

In summary, this work attempts to investigate the predictive power of a group of psychological variables on medical help-seeking behaviors and self-medication, suggesting mediator variables such as emotions or perception of symptoms.

\section{Method}

\section{Participants}

The parents of first-year psychology students filled in the set of self-reports that evaluate the variables of this study. The only restriction of the sample is that the participants were parents. When the students did not live with their parents, they were allowed to obtain the information from other people, with the only restriction that they had to be between the ages of 40 and 65 . A total of $5 \%$ of the sample was obtained this way, and despite the age limit restriction, some participants were less than 40 years of age. This sample selection procedure corresponded to the researchers' interest in selecting adult persons, whose health status might be more varied, and whose characteristics would be similar to those of the general population; that is, healthy and sick persons, workers, housewives, smokers and nonsmokers, etc.

Of the sample, $42 \%$ were men and $57 \%$ were women. The men's mean age was slightly higher than the women's (49.07 and 47.04 years, respectively), $F(1,481)=13.321, p$ $<.000$. Most had completed secondary education, although large percentages also had only completed primary education or had university studies, and $92 \%$ were married or lived with a partner. A more complete description of the sample can be found in Table 1.

\section{Variables and Measuring Instruments}

The variables of this study are assessed with a single questionnaire, which included the following measurement instruments:

\section{Criterion Variables}

Illness behavior. Self-report of frequency of visits to the doctor and consumption of drugs without medical prescription in the last month. The response options in both cases were: None, one or two, between three and five, five or more. 
Table 1

Distribution of Participants as a Function of Sociodemographic and Health-Related Variables

\begin{tabular}{lr}
\hline Sociodemographic Variables & $\%$ \\
\hline Sex & \\
Men & 42.5 \\
Women & 56.7 \\
Missing & 0.8
\end{tabular}

Age

$<40$ years

Between 40-50

4.0

Between 50-60

57.4

$>60$ years old

Missing

31.7

3.4

4.0

Marital status

Single

Married

Living with partner

Divorced

Widowed

\section{Education}

Can read and write

Primary school

29.3

Secondary school

University studies

Missing

Employment status

Working at home

Employee

Unemployed

Sick

Retired

Missing

\begin{tabular}{lr}
\hline Health-Related Behaviors & $\%$ \\
\hline Self-medication & \\
$\quad$ None & 69.5 \\
One or two & 21.6 \\
Between 3-5 & 2.8 \\
Five or more & 2.6 \\
Missing & 3.6 \\
& \\
Visits to the doctor visits in the last month & \\
None & 59.4 \\
One or two & 31.0 \\
Between 3-5 & 4.2 \\
Five or more & 1.8 \\
Missing & 3.6 \\
\hline
\end{tabular}

\section{Predictor Variables}

Self-report of symptoms (Somatic Symptoms Scale; Sandin \& Chorot, 1991). This self-report questionnaire gathers information about the frequency of symptoms during the last year. Although the instrument allows obtaining information on various symptoms from different biological systems, we limited it to a single score of the totality of the self-reported symptoms, with an internal consistency of $\alpha=.71$.

Reaction-to-stress personality type (Short Interpersonal Reactions Inventory-SIRI; Grossarth-Maticek \& Eysenck, 1990; adapted by Sandín, Chorot, Navas, \& Santed (1992). In the Spanish version, Type 1 (cancer prone), had an internal consistency of $\alpha=.70$, Type 2 (coronary heart disease prone) of $\alpha=.76$, Type 3 (hysterical personality) of $\alpha=.68$, Type 4 and $4 \mathrm{~b}$ (healthy autonomous personalities) of $\alpha=.81$ and $\alpha=.86$, respectively, Type 5 (rational/anti-emotional) of $\alpha=.53$, and Type 6 (psychopathic) of $\alpha=.70$

Life events (Life Experiences Survey; Saranson, Johnson, $\&$ Siegel, 1978). This instrument gathers information about various life events in the last 6 months and over the last year.

Coping style (Ways of Coping Checklist-WCC; Lazarus \& Folkman, 1985; Spanish adaptation by Rodriguez-Marín, Terol, Lopez-Reig, \& Pastor, 1992). In this version, we included positive thoughts $(\alpha=.76)$, blaming others $(\alpha=$ $.62)$, wishful thinking $(\alpha=.71)$, seeking social support ( $\alpha$ $=.68)$, planful problem solving $(\alpha=.74)$ emotional repression $(\alpha=.72)$, Looking for advantages $(\alpha=.68)$, Religiousness $(\alpha=.71)$, Self-blame $(\alpha=.62)$, resignation ( $\alpha=.56)$, and escape-avoidance $(\alpha=.40)$.

Attributional style (Attribution Style Questionnaire; Peterson et al., 1982). To measure attributional style, we used only the negative events. In our study, the following alpha values were obtained: Internality $(\alpha=.43)$, Stability $(\alpha=.56)$, Globality $(\alpha=.70)$, and Importance $(\alpha=70$.)

Health locus of control (Multidimensional Health Locus of Control-MHLC; Wallston, Wallston, \& Devellis, 1978). In our study, the following alpha values were obtained: Internality $(\alpha=.83)$, Other powerful people $(\alpha=.86)$, and Chance $(\alpha=.70)$.

Social support (Social Support Questionnaire; Saranson, Levine, Basham, \& Saranson, 1983). We used the short form. In our study, these alpha values were obtained: Selfreported support $(\alpha=.91)$ and Satisfaction with social support $(\alpha=.87)$.

Personal competence. We used the questionnaire created for this purpose by Peñacoba (1996). The author's version yields a single score of total competence, but, in our case, we factorized the questionnaire and generated five new subscales: (a) Assertiveness, $(\alpha=.70)$, (b) Self-control ( $\alpha=$ $.53)$, (c) Problem solving ( $\alpha=.62)$, (d) Empathy ( $\alpha=54$,) and (e) Social Support $(\alpha=.32)$, and Total Score $(\alpha=.78)$.

Personality dimensions. (Eysenck Personality Questionnaire; EPQ; Eysenck \& Eysenck, 1975). We used the 1992 Spanish version of Eysenck's dimensional model (neuroticism, extraversion, and psychoticism). 
Table 2

Descriptive Statistics of Psychological Variables and Symptoms

\begin{tabular}{|c|c|c|c|c|c|c|}
\hline Instrument & Variable & $N$ & Min. & Max. & $M$ & $S D$ \\
\hline \multirow{7}{*}{ SIRI } & Type 1 - Cancer prone & 498 & 0 & 10 & 4.12 & 2.22 \\
\hline & Type 2 - Cardiovascular prone & 498 & 0 & 10 & 2.93 & 2.63 \\
\hline & Type 3 - Hysterical & 498 & 0 & 10 & 2.89 & 1.72 \\
\hline & Type 4 -Autonomous & 498 & 0 & 10 & 6.76 & 1.69 \\
\hline & Type 4b -Autonomous & 498 & 1 & 10 & 7.65 & 2.04 \\
\hline & Type 5 - Rational/anti-emotional & 498 & 0 & 10 & 5.24 & 1.95 \\
\hline & Type 6 - Antisocial & 498 & 0 & 7 & 1.59 & 1.51 \\
\hline \multirow{3}{*}{ MHLC } & Internality & 498 & 10 & 42 & 26.25 & 5.59 \\
\hline & Other powerful people & 498 & 6 & 37 & 18.52 & 5.94 \\
\hline & Chance & 498 & 6 & 39 & 18.86 & 6.54 \\
\hline \multirow{3}{*}{ EPQ } & Neuroticism & 499 & 0 & 25 & 12.22 & 5.93 \\
\hline & Extraversion & 499 & 1 & 19 & 10.76 & 4.15 \\
\hline & Psychoticism & 499 & 0 & 12 & 1.88 & 1.68 \\
\hline \multirow{10}{*}{$\begin{array}{l}\text { Life Experiences } \\
\text { Survey }\end{array}$} & Number life events -6 months & 468 & 0 & 11 & 1.28 & 1.69 \\
\hline & Negative impact - 6 months & 464 & 0 & 85 & 5.85 & 9.47 \\
\hline & Positive impact - 6 months & 466 & 0 & 70 & 6.89 & 10.92 \\
\hline & Expectation - 6 months & 464 & 0 & 76 & 6.59 & 10.02 \\
\hline & Control - 6 months & 465 & 0 & 72 & 6.55 & 10.13 \\
\hline & Number life events - 1 year & 465 & 0 & 16 & 1.65 & 2.24 \\
\hline & Negative impact - 1 year & 459 & 0 & 75 & 7.78 & 12.14 \\
\hline & Positive impact - 1 year & 461 & 0 & 113 & 8.43 & 13.28 \\
\hline & Expectation - 1 year & 459 & 0 & 123 & 9.10 & 14.62 \\
\hline & Control - 1 year & 459 & 0 & 91 & 8.70 & 13.43 \\
\hline \multirow{11}{*}{$\begin{array}{l}\text { Ways of Coping } \\
\text { Checklist }\end{array}$} & Positive thoughts & 463 & 5 & 25 & 17.68 & 3.99 \\
\hline & Blaming others & 461 & 4 & 18 & 9.29 & 3.26 \\
\hline & Wishful thinking & 463 & 4 & 20 & 13.73 & 3.76 \\
\hline & Seeking social support & 463 & 3 & 15 & 9.58 & 3.04 \\
\hline & Planful problems solving & 463 & 5 & 25 & 16.32 & 4.20 \\
\hline & Emotional repression & 463 & 5 & 25 & 12.69 & 2.32 \\
\hline & Looking for advantages & 463 & 2 & 10 & 7.22 & 1.95 \\
\hline & Religiousness & 463 & 2 & 10 & 5.12 & 2.34 \\
\hline & Self-blame & 463 & 2 & 10 & 5.16 & 1.95 \\
\hline & Resignation & 463 & 2 & 10 & 5.65 & 1.96 \\
\hline & Escape-avoidance & 463 & 3 & 15 & 6.30 & 2.06 \\
\hline \multirow{4}{*}{$\begin{array}{l}\text { Attribution Style } \\
\text { Questionnaire }\end{array}$} & Internality & 469 & 6 & 42 & 23.96 & 5.87 \\
\hline & Stability & 469 & 8 & 42 & 22.70 & 5.71 \\
\hline & Globality & 468 & 6 & 42 & 19.19 & 7.27 \\
\hline & Importance & 466 & 10 & 42 & 30.57 & 6.03 \\
\hline \multirow{6}{*}{ Personal competence } & Total score & 443 & 33 & 75 & 56.2 & 6.63 \\
\hline & Assertiveness & 473 & 5 & 20 & 13.7 & 2.77 \\
\hline & Self-control & 484 & 3 & 12 & 8.7 & 2.53 \\
\hline & Problems solving & 491 & 4 & 12 & 9.4 & 1.75 \\
\hline & Empathy & 488 & 7 & 16 & 13.2 & 1.85 \\
\hline & Social support & 486 & 2 & 8 & 4.9 & 1.28 \\
\hline Social Support & Self-reported support & 468 & 1 & 54 & 24.45 & 11.80 \\
\hline Questionnaire & Satisfaction with social support & 470 & 6 & 36 & 31.03 & 4.65 \\
\hline \multicolumn{2}{|c|}{ Somatic Symptoms Scale } & 492 & 50 & 164 & 85.87 & 20.30 \\
\hline
\end{tabular}

Note. SIRI = Short Interpersonal Reactions Inventory; MHLC = Multidimensional Health Locus of Control; EPQ = Eysenck Personality Questionnaire. 


\section{Procedure}

Data was gathered from 501 subjects, all parents of $1^{\text {st }}$ , $2^{\text {nd }}$, and $3^{\text {rd }}$-year psychology majors at the Universidad Autónoma de Madrid. The questionnaires, included in a booklet, were handed out to the students, who were instructed to give them to their parents and then return them to the research team when they had been filled in. A total of 2000 booklets were sent, of which 501 were returned, so the final sample represents $25.05 \%$. To guarantee motivation and sincerity in the responses, respondents were offered the option of being informed of the results of their questionnaires. Eighty-eight percent of the sample ticked this option and their request was attended to by the research team.

The data were subjected to various statistical analyses with the SPSS 13.0 program. First, we calculated the descriptive statistics, frequencies of health-related behaviors, socio-demographic variables, lifestyles, and health problems, and the means, standard deviations, maximum and minimum scores for the rest of the variables. After the descriptive analysis, we proposed two structural equation models (LISREL 8.80) with the purpose of constructing a model that accounts for the criteria variables, the two health-related behaviors, and with the possibility of the predictors having direct effects on them, but also indirect effects through other variables. Structural equation models are specifically indicated for this purpose (Batista \& Coenders, 2000).
Dealing with self-reported variables considered as continuous variables, we decided to use the correlation matrix instead of the variance and covariance matrix (Batista \& Coenders), using the maximum likelihood estimation method.

\section{Results}

Of the sample, $69.5 \%$ had not taken medication without a prescription in the last month, whereas $21.6 \%$ had done so once or twice, $2.8 \%$ had done so between three and five times, and $2.6 \%$ more than five times. With regards to visits to the doctor, $59.4 \%$ had not made any visits in the last month, $31.0 \%$ had gone to the doctor between one and two times, $4.2 \%$ between three and five times, and $1.8 \%$ more than five times. In both cases, there were $3.6 \%$ of unknown values. The analysis of the correlation for ordinal variables shows that these variables do not appear to be related to each other, Spearman's $\rho=-.046, n s$; Kendal's $\tau=-.043$, $n s$. Table 2 presents the scores obtained for the rest of the variables considered.

In Figures 1 and 2 are shown the two structural equation models that were created to contrast the two criteria variables analyzed in this study, self-reported frequency of selfmedication and the frequency of visits to the doctor in the last month. In both cases, the direct effects of some of the psychological variables analyzed were observed, whereas

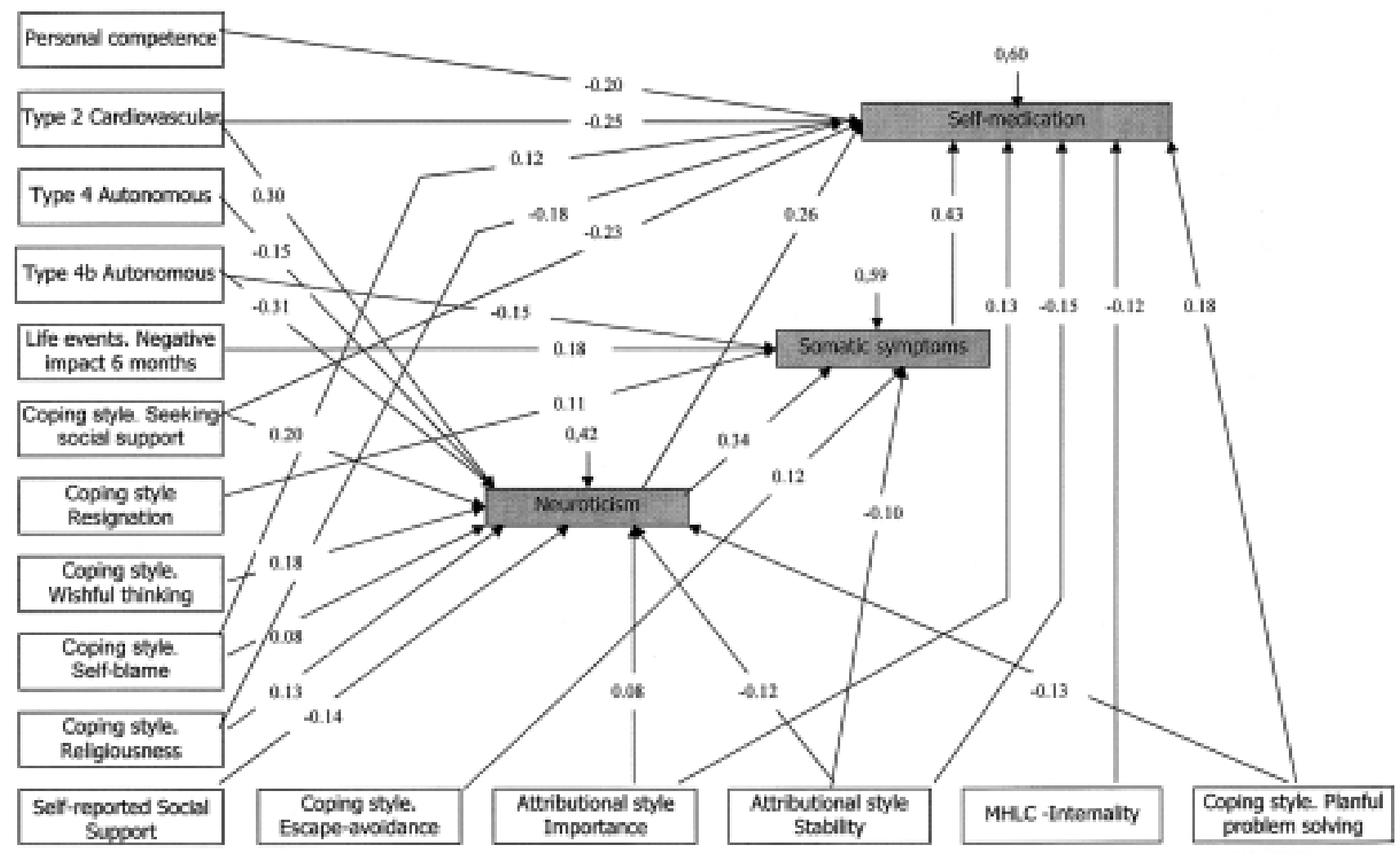

Figure 1. Structural equation model for the variable self-medication. 


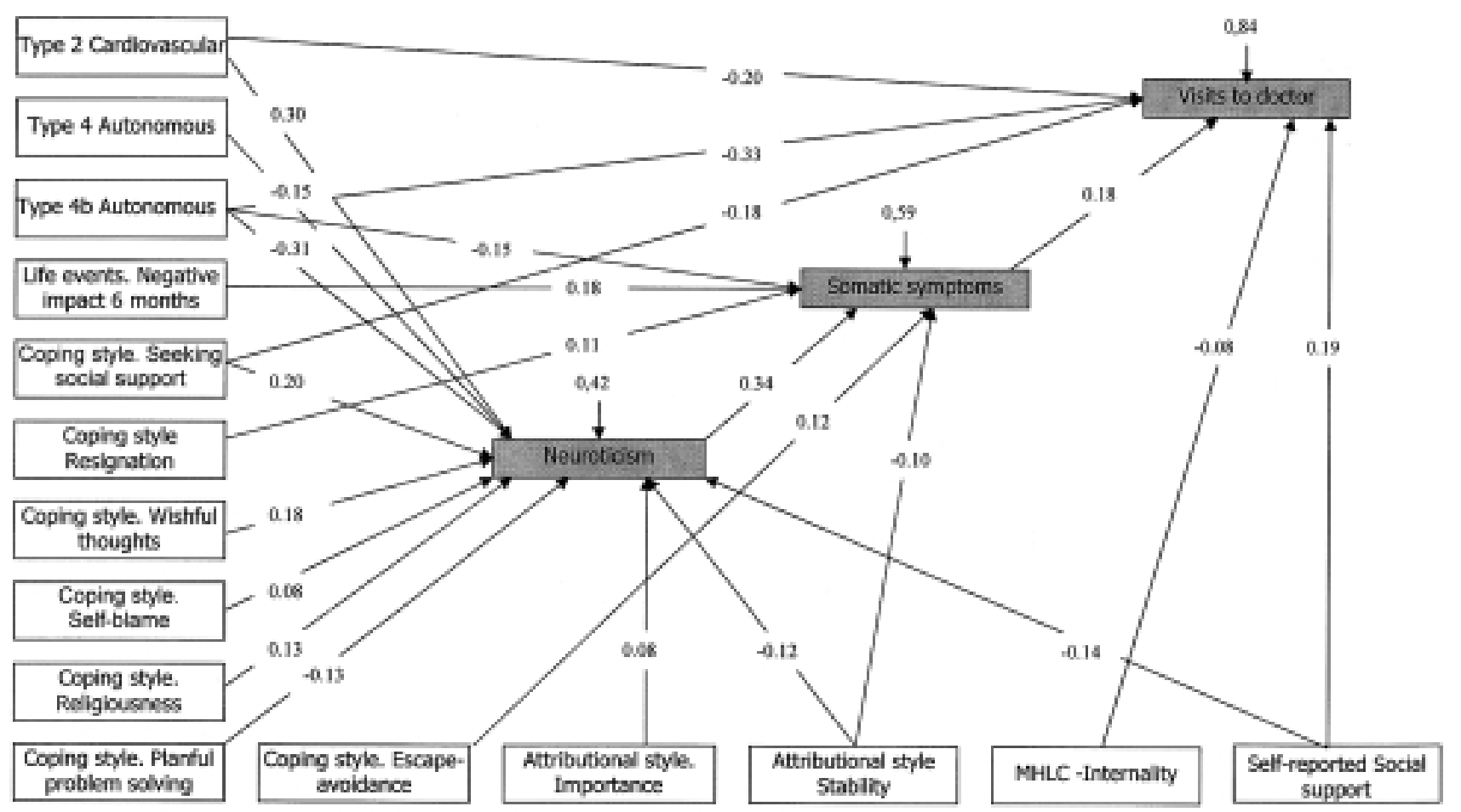

Figure 2. Structural equation model for the variable visits to the doctor.

in other cases, these effects were mediated by other variables, such as neuroticism and perceived symptoms. Model fit was evaluated with the chi-square statistic and by means of the root mean square error of approximation (RMSEA), the goodness-of-fit index (GFI), and the nonnormed fit index (NNFI). In both cases, the two models presented a good fit: self-medication: $\chi^{2}(23, N=501)=30.18, p=.1443$, RMSEA $=.025, \mathrm{GFI}=.994, \mathrm{NNFI}=.976$; visits to the doctor, $\chi^{2}(25, N=501)=24.97, p=.46392$, RMSEA $=$ .000 , GFI $=.994$, NNFI $=.998,$. Thus, the proposed equations account for the structure of the data, establishing the relationship between them. In addition to the global fit of the models, we emphasize that all the relationships proposed were observed to be statistically significant.

Therefore, with regard to self-medication, the model accounts for $40 \%$ of the variance. The variables that had a direct and positive effect on the variance were symptom perception $(\beta=.43)$, neuroticism $(\beta=.26)$, planful problem solving coping style $(\beta=.18)$, the importance attributed to negative events $(\beta=.13)$, and self-blame coping style $(\beta=$ .12). In contrast, other variables affected self-medication indirectly and negatively, that is, the higher the score in these variables, the lower the probability of self-medication. Among these variables were Personality Type 2 and cardiovascular predisposition $(\beta=-0.25)$, personal competence $(\beta=-.20)$, social support-seeking coping styles $(\beta=-.23)$, religiousness ( $\beta=-.18)$, stable attributions of events $(\beta=-.15)$, and the belief in internality as a health determinant $(\beta=-.12)$. Other variables had an indirect effect on self-medication; specifically, the positive effect of the negative impact of stressors from the last six months emerges through the symptoms, resignation and escape as coping styles, and neuroticism. This group of variables conjointly explains $41 \%$ of the variance of the symptoms. Neuroticism had a direct effect on self-medication, an indirect effect through the symptoms, and at the same time, it was the mediator variable by which other variables affected perception of symptoms and self-medication. These variables were: personality Types 2, 4, and 4-b, social support-seeking coping styles, wishful thinking, self-blame, resignation, and planful problem solving, social support, and the attribution of negative, stable events of importance. This group of variables accounts for $58 \%$ of the variance of neuroticism and the weights of each variable can be observed in Figure 1.

The group of variables commented on above also accounted for visits to the doctor, but with less efficiency, as they only accounted for $16 \%$ of the variance of this variable. Nonetheless, neither the relationships with the variables, nor the weights are the same as in the previous case. Therefore, a group of predictors with direct effects appeared, but with a different configuration. The most relevant variables were those that had an inverse relationship with visits to the doctor-Type 4-b $(\beta=-.33)$ and Type 2 ( $\beta=-.20)$, social support-seeking coping style $(\beta=-.18)$, and the belief in internal health determinants $(\beta=-.08)-$ whereas somatic symptoms $(\beta=.18)$ and social support $(\beta$ $=.19$ ) were directly related to visits to the doctor. Amongst the indirect effects, we must emphasize that all these effects 
were through somatic symptoms instead of through neuroticism, as, in this case, there was no relationship between neuroticism and the visits to the doctor. The rest of the indirect effects are the same as those mentioned in the case of self-medication. In Figure 2, they are displayed in more detail and with the weight of each variable.

\section{Discussion}

This study was designed to test the hypothesis that various psychological variables predict various health-related behaviors. We also aimed to test the predictive capacity of the Grossarth-Maticek types compared to other psychological variables related to stress. For these purposes, we selected as criterion variables two illness behaviors performed by the subjects: seeking professional help (or visits to the doctor) and resorting to self-medication (Gijsbers van Wijk \& Kolk, 1997).

The results show that both criteria are related to psychological determinants and that such determinants can, to a great extent, account for part of their variance, revealing the utility and the need for a multivariable focus in the field of health psychology. Moreover, we have shown that the criteria are independent of each other and that the group of predictors accounts for them in different ways: Almost twice as much variance is accounted for in the case of selfmedication as in the case of visits to the doctor. This may also be due to the fact that these behaviors are carried out by people in different situations. For example, when observing clear and precise symptoms of which they have had prior experience, and if visiting the doctor involves some expense, people may resort to self-medication, whereas people with chronic illnesses, diffuse symptoms, and perceived severity (weight loss or breathing difficulties) will go to the doctor to ask for tests or for prescription medication (Caamaño et al., 2000). We also point out that although some predictors are the same ones and with similar behaviors-Type 2 personality (heart disease proneness) or the belief in internality as a health determinant-in other predictors, the relative eight is very different, such as the case of perceived symptoms, which play a central role in self-medication, but a secondary role in visits to the doctor.

Visits to the Doctor. Seeking medical care is one of the variables that arouses the most interest in the field of illness behaviors. Researchers are aware of the implications of this behavior and its determinants for planning health services. Our work shows that there is a direct relationship between some of Grossarth-Maticek and Eysenck personality types and this behavior but, contrary to our expectations, both Type 4 (autonomous) and Type 2 (coronary disease prone) are related to less frequent use of the health services. Although this result can be expected in the case of the healthy typology, in the case of the coronary disease prone type, it should be interpreted as another characteristic of the type. However, when faced with a health problem, this can be a risk factor. Internality health beliefs and social support-seeking coping styles also have an inverse effect on visits to the doctor, although in different ways: The presence of social support is related to the frequency of visits to the doctor. As expected, perceived symptoms were also directly related to the criteria variables, but with less weight than personality or social support variables. These data support the models that associate visits to the doctor with the perception of symptoms and with social support. From different models (Gijsbers van Wijk \& Kolk, 1997; Rodríguez-Marin, 1995), it is assumed that these two variables, together with the expense of the visits to the doctor and previous experiences, determine whether or not a person seeks professional help. In another structural equation model, Kolk, Hanewald, Schagen and Gijsbers van Wijk (2002) found that suffering from a chronic disease and the self-reported symptoms predict the frequency of visits to the doctor. However, when self-reports are used to measure the variables, common symptoms and sociodemographic variables correlate with visits to the doctor. AlWindi, Dag, and Kurt (2002) also reported support for perceived symptoms, together with sleeping problems and perceived health, determining the frequency of visits to the doctor, whereas other studies associate various types of social support with this behavior (McCullough, Hoyt, Larson, Koenig, \& Thoresen, 2000; Wilcox, Aragaki, Mouton, Evenson, \& Wassertheil-Smoller, 2003). Support is also found for the effect of psychological variables on visits to the doctor when the type of health service used is not conventional, but rather some kind of alternative medicine (Petrie et al., 2001). Various studies have shown that other psychological variables, such as self-efficacy, optimism, health locus of control, emotional stability (Artisticio, Baldassarri, Lauriola, \& Laicardi, 2000), or Grossarth-Marticek's (Larson et al., 1995) personality types are also related to visits to the doctor, but our study makes the direct relation to this behavior relative.

Self-medication. Taking drugs without a medical prescription can be considered an alternative to visiting a doctor when the person perceives the symptoms and interprets them as problems. Psychological variables emerged as the main determinants of self-medication, specifically, perception of symptoms, neuroticism, planful problemsolving or self-blame coping styles, and the importance attributed to negative events. In contrast, personal competence, neuroticism, Grossrth-Maticek and Eyensenck's personality types 2 and 4, religiousness, the perception of instability of negative events, and the belief in internal determinants of health act as protectors. These data confirm the importance of stress in health-related behaviors and point to the importance of coping, as it is not life events per se that condition self-medication, but rather their negative impact. The theoretical models of stress could account for our results, although they are not usually applied to selfmedication. Just as Cohen and Williamson's (1991) model explains the frequency of visits to the doctor through the 
perception of symptoms of stress and labeling them as signs of illness, in this situation, self-medication is just another option that also depends on other factors analyzed in our study. Some of these factors predict that self-medication will not appear. Examples are personal competence, which protects against stress, and the belief that health depends on internal factors (Wallston et al., 1994). A previously cited study by Kolk et al. (2002) found that perceived symptoms correlate with the use of various health services and attribution processes, while finding an additional effect for negative affectivity. An especially interesting and novel result is the relationship found between types of stress reaction and neuroticism and the practice of self-medication. This behavior can have important consequences on health, because although it can often be an option for unimportant health problems, on many occasions, it involves more risk than benefit. In our case, it can be an indicator of health in the population and our results again confirm the importance of psychosocial variables in health, variables that should be taken into account when analyzing the determinants of selfmedication (Caamaño et al., 2000).

From this study, it is noted that that psychosocial variables do not only have a direct effect on health behaviors, but the effects of other variables, such as neuroticism, the negative impact of vital events, and some coping styles, such as resignation or escape, are mediated by the perception of symptoms. Likewise, other variables also exert an influence on health through a lower predisposition to symptom perception, either because of autonomous features (Grossarth-Maticek and Eysenck's Type 4) or because of the perception of instability of a vital event. Other studies have shown that other psychological variables also correlate with self-reported symptoms: anxiety and depression (Al-Windi, 2004), personality, coping styles, and social support (Sharpley, Dua, Reynolds, \& Acosta, 1995) and the effect of stress (Stock et al., 2003). The findings of our study could be notably strengthened by studying various indirect symptom-mediated effects, because, for example, the relationship between neuroticism and symptoms is well established, but neuroticism, in turn, may be related to some health-related behaviors, but not directly (Saboonchi \& Lundh, 2003; Wollrath, Knoch, \& Cassano, 1999).

An addition, neuroticism deserves special attention. Our findings revealed that it has direct effects on health behaviors, in the case of self-medication, and via the perception of symptoms, it also affects the frequency of visits to the doctor. However, in this case, it may be a good indicator of people's emotional state, and through these emotions, other psychosocial variables may affect health, similarly to most of the coping styles or the attributive style. The same is observed with Grossarth-Maticek and Eysenck's personality types, which are associated with neuroticism in different ways, so that the diverse profiles they present is confirmed (Orejudo, Froján, \& Malo, 2004).
In summary, this study has shown that psychological variables can predict different health variables independently. These health variables could be included with variables that have traditionally been called illness behaviors (Galán et al., 2000). In addition to the direct and independent effect of variables such as social support, the negative impact of life events, personal competence, personality, or diverse health-related beliefs, we point out the relevance of the perception of symptoms in all the variables studied, as this variable is, in turn, highly determined by psychological variables. These results show that a multivariable focus is much more useful to study the determinants of the levels of health in the population than a specific strategy based solely on the analysis of isolated variables. In this sense, models that include mediator variables can clarify this field, in which there is a great variety of theoretical proposals that can sometimes be complementary.

Regarding Grossarth-Maticek and Eysenck's types, they are useful health predictors, and they predict independently of other variables in the field, but we were unable to confirm the relevance found in the original studies (Grossarth-Maticek et al., 1988). Moreover, it seems that, in some cases, the effects on behavior can be direct, but in others, as with the other psychological variables, it is preferable to propose models of health in which the effects are measured through other variables, such as the perception of symptoms or neuroticism. In support of this hypothesis, it can be highlighted that the series of psychological variables studied on herein serve to differentiate the types and that some of them have direct influence on the perception of symptoms (Orejudo et al., 2004).

\section{References}

Al-Windi, A. (2004). Determinants of complaint symptoms in a Swedish health care practice. Results of a questionnaire survey. Journal of Psychosomatic Research, 56, 1-9.

Al-Windi, A., Dag, E., \& Kurt, S. (2002). The influence of perceived well-being and reported symptoms on health care utilization: A population-based study. Journal of Clinical Epiedemiology, 55, 60-66.

Amelang, M. (1997). Using personality variables to predict cancer and heart disease. European Journal of Personality, 11, 319342.

Amelang, M., \& Schmitdt-Rathjens, C. (1996). Personality, cancer and coronary heart disease: Further evidence on a controversial issue. British Journal of Health Psychology, 1, 191-205.

Andrykowski, M., \& Brady, M.J. (1994). Health locus of control and psychological distress in cancer patients: Interactive effects of context. Journal of Behavioral Medicine, 17, 5, 439-458.

Artístico, D., Baldassarri, F., Lauriola, M., \& Laicardi, C. (2000). Dimensions of health-related dispositions in elderly people: Relationship with health behaviour and personality traits. European Journal of Personality, 14, 533-552. 
Barrón, A., \& Chacón, F. (1990). Lugar de control para la salud: su efecto protector frente a los acontecimientos vitales estresantes. Investigaciones Psicológicas, 8, 231-237.

Batista, J.M., \& Coenders, G. (2000). Modelos de ecuaciones estructurales. Madrid: Editorial La Muralla.

Bermúdez, J. (1999). Personality and health-protective behaviour. European Journal of Personality, 13, 83-103.

Caamaño, F., Figueiras, A., Lado, E., \& Gestal-Otero, J.J. (2000). La automedicación: concepto y perfil de sus "usuarios". Gaceta Sanitaria, 14, 294-299.

Cohen, S., \& Williamson, G.M. (1991). Stress and infectious disease in humans. Psychological Bulletin, 109, 5-24.

Dua, J. (1994). Comparative predictive value of attribution style, negative affect and positive affect in predicting self-reported physical health and psychological health. Journal of Psychosomatic Research, 38, 7, 669-680.

Eysenck, H.J. (1985). Personality, cancer and cardiovascular disease: A causal analysis. Journal of Psychosomatic Research, 5, 535557.

Eysenck, H.J. (1991). Smoking, personality and stress. New York: Springer-Verlag.

Eysenck, H.J., \& Eysenck, S.B.G. (1975). Manual of the Eysenck Personality Questionnaire. London: Hodder \& Stoughton [Spanish translation: EPQ. Cuestionario de Personalidad para niños (EPQ-J) y adultos (EPQ-A). Madrid: TEA, 1992].

Eysenck, H.J., Grossarth-Maticek, R., \& Everitt, B. (1991). Personality, stress, smoking, and genetic predisposition as synergistic risk factors for cancer and coronary heart disease. Integrative Physiological and Behavioral Science, 26, 309-322.

Friedman, H.S. (1990). Personality and disease: Overview, review and preview. In H.S. Friedman (Ed.), Personality and disease (pp. 3-13). New York: Wiley \& Sons.

Friedman, M., \& Roseman, R.H. (1959). Association of specific overt behavior pattern with blood and cardiovascular findings. Journal of the American Medical Association, 169, 1286-1296.

Galán, A., Blanco, A., \& Pérez, M.A. (2000). Análisis del concepto de conducta de enfermedad: un acercamiento a los aspectos psicosociales del enfermar. Anales de Psicología, 16, 157-166.

Gijsbers van Wijk, C.M.T., \& Kolk, A.M. (1997). Sex differences in physical symptoms: The contribution of symptom perception theory. Social Science and Medicine, 45, 231-246.

Grossarth-Maticek, R., \& Eysenck, H.J. (1990): Personality, stress and disease: Description and validation of a new inventory. Psychological Reports, 66, 355-373.

Grossarth-Maticek, R., Eysenck, H.J., \& Vetter, H. (1988). Personality type, smoking habit and their interaction as predictors of cancer and coronary heart disease. Personality and Individual Differences, 9, 479-495.

Kiecolt-Glaser, J.K. \& Chee, M.A. (1991). Personality, Stress and Cancer: A Re-examination. Psycohological Inquiry, 2, 249251.

Kolk, A.M.M., Hanewald, G.J.F.P., Schagen, S., \& Gijsbers van Wijk, C.M.T. (2002). Predicting medically unexplained physical symptoms and health care utilization. A symptom-perception approach. Journal of Psychosomatic Research, 52, 35-44.
Kubzansky, L.D., \& Kawachi, I. (2000). Going to the heart of matter: Do negative emotions cause coronary heart disease? Journal of Psychosomatic Research, 48, 323-337.

Larsson, G., Nordström, L., Ljunggren, G., \& Nyberg, A.B. (1995). The Grossarth-Maticek and Eysenck personality types, healthrelated behaviour, and indicators of transitory ill-health. European Journal of Personality, 9, 75-87.

Lazarus, R.S., \& Folkman, S. (1984). Stress, appraisal and coping, New York: Springer.

Matthews, G., Yousfi, S., Schmidt-Rathjens, C., \& Amelang, M. (2003). Personality variable differences between disease clusters. European Journal of Personality, 17, 157-177.

McCullough, M.E., Hoyt, W.T, Larson, D.B., Koenig, H.G., \& Thoresen, C. (2000). Religious involvement and mortality: A meta-analytic review. Health Psychology, 19, 211-222.

O'Carrol, R.E., Smith, K.B., Grubb, N.R., Fox, K.A.A., \& Masterton, G. (2001). Psychological factors associated with delay in attending hospital following a myocardial infarction. Journal of Psychosomatic Research, 51, 611-614.

Orejudo, S., Froján, M.X., \& Malo, C. (2004). La tipología de personalidad de Grossarth-Maticek y Eysenck. Relación con otros constructos psicológicos. Psiquis,_25, 152-166.

Pelechano, V. (2006, September). Un modelo multinivel de personalidad en la enfermedad crónica: sugerencias y resultados. VIII Congreso Internacional sobre Estudio de la Conducta. Santiago de Compostela, Spain.

Peñacoba, C. (1996). Estrés, salud y calidad de vida: Influencia de la dimensión cognitivo-emocional. Unpublished doctoral dissertation. Universidad Autónoma de Madrid.

Peterson, C., \& Seligman, M.E. (1987). Explanatory style and illness. Journal of Personality, 55, 237-265.

Peterson, C., Semmel, A., Von Baeyer, C., Abramson, L.Y., Metalsky, G.I., \& Seligman, M.E. (1982). The attributional style questionnaire. Cognitive Therapy and Research, 6, 287-299.

Petrie, J., Sivertsen, B., Hysing, M., Broadbent, E., Moss-Morris, R., Eriksen, H.R., \& Ursin, H. (2001). Thoroughly modern worries. The relationship of worries about modernity to reported symptoms, health and medical care utilization, Journal of Psychosomatic Research, 51, 395-401.

Petticrew, M., Fraser, J.M., \& Regan, M.F. (1999). Adverse lifeevents and risk of breast cancer: A meta-analysis. British Journal of Health Psychology, 4, 1-17.

Price, M.A., Tennant, C.C., Butow, P.N., Smith, R.C., Kennedy, S.J., Kossoff, M.B., \& Dunn, S.M. (2001). The role of psychosocial factors in the development of breast carcinoma: Part II. Life events stressors, social support, defense style, and emotional control. Cancer, 91, 686-697.

Quander-Blaznik, J. (1991). Personality as predictor of lung cancer: A replication. Personality and Individual Differences, 12, 125130.

Rodríguez-Marín, J. (1995). Psicología social de la salud. Madrid: Síntesis Psicología.

Rodríguez, A.M., Lemos, S., Canga, A. (2002). Variables biológicas, conductuales y de personalidad como predictores de salud: un estudio longitudinal. Psicología Conductual, 10, 7-29. 
Rodríguez-Marín, J., Pastor, M.A., \& López-Reig, S. (1993). Afrontamiento, apoyo social, calidad de vida y enfermedad. Psicothema, 5(Suppl.), 349-372.

Rodriguez-Marín, J., Terol, M.C., López-Reig, S., \& Pastor, M.A. (1992). Evaluación del afrontamiento del estrés: propiedades psicométricas del cuestionario de formas de afrontamiento de acontecimientos estresantes. Revista de Psicología de la Salud, 4, 59-84.

Saboonchi, F., \& Lundh, L.G. (2003). Perfectionism, anger, somatic health, and positive affect. Personality and Individual Differences, 35, 1585-1599.

Sandín, B., \& Chorot, P. (1991, September). Escala de síntomas somáticos. III Congreso de Evaluación Psicológica. Barcelona.

Sandín, B., Chorot, P., Jiménez, M.P., \& Santed, M.A. (1994). Stress behavior types, psychosomatic complaints and disease. Stress News, 5, 4-9.

Sandín, B., Chorot, P., Navas, M.J., \& Santed, MA. (1992). Estrés y enfermedad: Inventario de Reacciones Interpersonales de Grossarth-Maticek y Eysenck. Revista de Psicología General y Aplicada, 45, 391-396.

Saranson, I.G., Johnson, J.H., \& Siegel, J.M. (1978). Assessing the impact of life changes: Development of the Life Experiences Survey. Journal of Consulting and Clinical Psychology, 46, 932-946.

Saranson, I.G., Levine, H.M., Basham, R.B., \& Saranson, B. (1983). Assessing social support: The Social Support Questionnaire. Journal of Personality and Social Psychology, 44, 127-139.

Scheier, M.F., \& Carver, C.S. (1992). Effects of optimism on psychological and physical well-being: Theoretical overview and empirical update. Cognitive Therapy and Research, 16, 201-228.

Schmitz, P.G. (1992). Personality, stress-reactions and disease. Personality and Individual Differences, 13, 683-69.

Sharpley, C.F., Dua, J.K., Reynolds, R., \& Acosta, A. (1995). The direct and relative efficacy of cognitive hardiness, type A behaviour pattern, coping behaviour and social support as predictors of stress and ill-health. Scandinavian Journal of Behaviour Therapy, 24, 15-29.
Smedslund, G. (1995). Personality and vulnerability to cancer and heart disease: Relations to demographic and life-style variables. Personality and Individual Differences, 19, 691-697.

Smith, T.W., \& Ruiz, J.M. (2002). Psychosocial influences on the development and course of coronary heart disease: Current status and implications for research and practice. Journal of Consulting and Clinical Psychology, 70, 548-568.

Stock, C., Kücük, N., Miseviciene, I, Habil, F, Guillén-Grima, F, Petkeviciene, J., Aguinaga-Ontoso, I., \& Kramer, A. (2003). Differences in health complaints among university students from three European countries. Preventive Medicine, 37, 535-543.

Wallston, B.S., Wallston, K.A., Kaplan, G.D., \& Maides, A. (1976). Development and validation of the Health Locus of Control (HLC) Scale. Journal of Consulting and Clinical Psychology, 44, 580-585.

Wallston, K.A., Wallston, B.S., \& Devellis, R. (1978). Development of the Multidimensional Health Locus of Control (MHLC) Scales. Health Education Monographs, 6, 160-170.

Wallston, K.A., Stein, M.J., \& Smith, C.A. (1994). Form C of the MHLC scales: A condition-specific measure of locus of control. Journal of Personality Assessment, 63, 534-553.

Watson, D., \& Clark, L.A. (1984). Negative affectivity: The disposition to experience adverse emotional states. Psychological Bulletin, 96, 465-490.

Watson, D., \& Pennebaker, J.W. (1989). Health complaints, stress, and distress: Exploring the central role of negative affectivity, Psychological Review, 96, 234-254.

Wilcox, S., Aragaki, A., Mouton, C.P., Evenson, K.R., WassertheilSmoller, S., \& L.B. (2003). The effects of widowhood on physical and mental health, health behaviors, and health outcomes: The women's health initiative, Health Psychology, 22, 513-522.

Wollrath, M., Knoch, D., \& Cassano, L. (1999). Personality, risky health behavior, and perceived susceptibility to health risks. European Journal of Personality, 13, 39-50.

Received February, 15, 2006 Revision received March, 5, 2007 Accepted March, 14, 2007 